\title{
Exotic deer in southern Latin America: what do we know about impacts on native deer and on ecosystems?
}

\author{
Werner T. Flueck
}

Received: 17 June 2009/Accepted: 10 October 2009/Published online: 23 October 2009

(C) Springer Science+Business Media B.V. 2009

\begin{abstract}
A recent review on exotic cervids concluded that deer introduced to Patagonia impacted habitat and native huemul deer Hippocamelus bisulcus. I evaluate these assertions and amend information about this South American case study. Categorizing deer along narrow characteristics may be too restrictive to allow accurate predictions about interactions. More effective is considering the magnitude of plasticity (behavioral, phenotypic, genetic). The dichotomy of native versus exotic deer masks situations where prevailing ecological conditions are far from 'native', such as absence of predators, and such results from artificial settings have limitations. Studies used to contrast effects on vegetation from exotic red deer (Cervus elaphus) versus native huemul did not analyze native deer and provided no data to support conclusions in the review. Huemul were concluded to have high trophic overlap with red deer whose diet, however, was determined in another
\end{abstract}

W. T. Flueck

National Council for Scientific Research,

C.C. 176, 8400 Bariloche, Argentina

W. T. Flueck (ه)

Institute of Natural Resources Analysis, Universidad

Atlantida Argentina, Mar del Plata, Argentina

e-mail: wtf@deerlab.org

W. T. Flueck

Swiss Tropical Institute, University Basel,

Basel, Switzerland habitat where the food item of supposed major overlap was absent, and suggesting that red deer might cause exploitation competition was not supported by cited data. There was no mention that huemul are foremost exposed to livestock rather than exotic deer. Concluding that exotic prey including red deer increase predator density resulting in increased predation of huemul (apparent competition), was not supported by cited studies. To the contrary, highdensity puma (Puma concolor) could not prevent guanaco (Lama guanicoe) from increasing $>13$-fold, nor that huemul expanded into these sites. Not only were those studies opposite to conclusions in the review, but none had studied huemul nor predator population trends. Data from little known species like huemul should be used with reservations when aiming at generalizations.

Keywords Invasion - Cervus elaphus . Introduction · Argentina - Alien · Exotic · Invasive species - Hippocamelus bisulcus . Dietary overlap · Habitat impacts . Interspecific competition

\section{Introduction}

Translocations and introductions of cervids to novel regions date back at least to Phoenician sailors who introduced fallow deer (Dama dama) to locations 
around the Mediterranean (Masseti and Mertzanidou 2008). Romans followed by bringing fallow deer to northern Europe, and in the 10th century Normans introduced the same to Britain. Since that time, with all continents having received exotic cervids, much information has accumulated about such liberations. Introductions have occurred under many different settings: New Zealand (NZ) lacked native terrestrial mammals (except bats) and Australia lacked eutherian herbivores; Saint George's island lacked native herbivores and large predators; while other regions contained either native cervids and large predators, or native cervids with large predators already exterminated (Lever 1985; Leader-Williams 1988; King 1990). Although a few introductions involved only one cervid, most cases involved mixtures of introduced ruminants, including domestic ones, some of which became feral. The subsequent population dynamics of a given introduced cervid and their environmental impacts resulted thus in many different outcomes. There are inherent problems when reviewing such complex multifactorial biological interactions on a global scale in search of generalizations. For one, limited data results in tradeoffs between providing a reasonable number of examples and using examples with well-founded conclusions. Although generalizations about impacts of exotic on native cervids and ecosystems are a promising avenue in search of management recommendations, it is misfortunate when emphasis is placed on examples of poorly known species which thus have many basic biological and ecological issues pending to be understood. Reliance on weak sources of information can lead to increased variation when making generalizations, and if erroneous, will likely perpetuate dogmas based on outdated or wrong information about the focal species used for the analysis.

In this paper I analyze evidence put forth by Dolman and Wäber (2008, D\&W) in their review of impacts of exotic deer on native deer and their ecosystems where they used examples from Europe, South America, Australia and NZ in an attempt to find general global patterns and to reveal the scale of such detrimental impacts. I will address the utility of categorizing cervids along narrow ecological criteria, the dichotomy of native versus exotic deer, the impact of exotic deer on forests, and the existence of exploitation and apparent competition. My other objectives are to add to and amend information provided by $\mathrm{D} \& \mathrm{~W}$ on their case from South America about exotic deer impacting native deer, and to show that information available on poorly known species should be used with due reservations when making generalizations. Although D\&W used the cold-temperate huemul (Hippocamelus bisulcus) to illustrate their main arguments, Flueck and Smith-Flueck (2006a) pointed out that even basic information on this species and on most of its subpopulations is very scarce, having found only nine original studies on a Cross-Search of ISI Web-of-Knowledge and 17 external databases (1945-2006). Additional information on huemul from grey literature and unpublished reports has been summarized by Diaz and SmithFlueck (2000), but was not included in the review by D\&W. Among fundamental needed conservation actions, IUCN thus recommended increasing wellfounded knowledge on the ecology and biology of huemul and factors preventing its recovery (Jiménez et al. 2008).

\section{The utility of categorizing cervids along narrow ecological criteria}

Categorizing cervids based on their ecological characteristics allows predictions of interactions, and therefore, the possibility to anticipate degrees of impact from an exotic deer on native ones or on ecosystem components. The accuracy and value of such predictions are linked directly to the precision of characterizing ecological attributes of interacting species. For instance, if a native deer is a strict concentrate selector, but the exotic deer is a strict grazer, one can assume that there is little impact from the exotic species, at least in terms of diet. Nonetheless, the most important attributes are related to the variance in all biological responses (intraspecific variation) that a given species is able to express (e.g. West-Eberhard 1989). This plasticity has different origins, such as behavioral, phenotypic, or genetic. Fallow deer, for instance, respond differently according to environmental settings. When sympatric with other cervids in a modified environment (e.g. enclosures or feeding stations) lacking a large predator community, they were effective competitors, as reviewed by D\&W. Yet though widely introduced in Patagonia, they remain in low numbers compared to red deer (Cervus elaphus), guanaco (Lama 
guanicoe) and livestock. Possibly their lack of defenses against native predators is preventing a stronger population growth rate. Even well studied deer continue to surprise us with their repertoire of possible responses: who anticipated a red deer female capable of driving a Patagonian puma (Puma concolor) - a hungry female with a cub-up a tree (Flueck 2004)? Meanwhile lesser-known species, like huemul, are unknown with respect to their plasticity (Diaz and Smith-Flueck 2000).

The frequently used classification of species according to major patterns has inherent limitations. For instance, dietary patterns of reindeer (Rangifer tarandus) from Saint George island, Svalbards, or Alaska differ substantially, and reindeer have large intraspecific variations creating a continuum from selective feeding to generalist feeding behavior (Skogland 1984). Similarly, mule deer (O. hemionus) or white-tailed deer (O. virginianus) occur from high precipitous mountains resulting in migratory behavior, to flat grassland, and desert environments. Whitetailed deer have a natural distribution stretching from North to South America (i.e. Venezuela, Columbia, Peru, Argentina and Brazil), while exhibiting tremendous plasticity. Accordingly, highly plastic species do not lend themselves to restrictive classifications, and splitting cervids along narrow ecological criteria does not allow room for the more important measure of plasticity in adaptations as the basis for their capacity to deal with novel situations.

\section{The dichotomy of native versus exotic deer regarding their effects on ecosystems}

Opposing native versus exotic deer has some useful applications. However, I posit that if evolutionaryecological phenomena are of primary interest, then "native" as a distinguishing concept is insufficient. Whereas a species is native based on paleontological data, prevailing environmental and ecological conditions might be far from "native", evolutionarily speaking. For instance, the large predator community previously acting on deer in the United Kingdom is now exterminated. Another case is native red deer in the Swiss National park which were completely exterminated by the 18th century along with all large predators. Whereas red deer recolonized the area shortly after 1900, all mayor predators have remained extinct. Thus, characteristics of subsequent population dynamics of this red deer population with their environmental impacts and behavioral patterns resulted not from an evolutionarily intact setting, but rather from an artificial one (Haller 2002). Besides affecting prey mortality rates, predators have an important role through nonconsumptive effects in structuring ecological communities (Flueck 2000; Pierce et al. 2004). Nonlethal effects on prey include reducing their activity times, altering their habitat use, increasing their group size, or changing their vigilance levels, which on a population level may actually be more important than lethal effects (Altendorf et al. 2001; Pyare and Berger 2003; Creel and Christianson 2008). Study results from artificial and ecologically incomplete settings thus have their limitations.

D\&W misapplied the term keystone to overabundant deer. They did not distinguish between native deer in artificial versus in ecologically complete settings and consequently their application of the concept of keystone species for native deer only further compounds confusion around this term, which, though elusive and poorly defined, is still broadly applied (Mills et al. 1993; Payton et al. 2002). Identifying keystone species can be problematic, and in addition the concept imposes a rigid structure on species interactions, as interactions or their strengths are constant in space and time (Mills et al. 1993; Payton et al. 2002). As originally applied, a keystone species is rare in occurrence but has a disproportionally high impact (Paine 1966). This fits large predators acting on ecosystems through suppressing ungulates (Henke and Bryant 1999; Flueck 2000; Berger et al. 2001; Ripple and Beschta 2008; Beschta and Ripple 2009). In contrast, substantially reducing or removing the effect of large predators through anthropogenic agents concomitantly results in a numeric response of native prey populations, who then increase the strength of interaction with their food base, thereby inducing major changes in the ecosystem. While cervids have the inherent capacity to reach densities such that they can drive an ecosystem into another state, this does not qualify them as a keystone species. For one, this outcome has never been described for intact ecosystems containing pristine vegetation structure and complete herbivore and predator communities (Messier and Crete 1985; Tomialojc 1991; Breitenmoser and Haller 1993; 
Jedrzejewski et al. 1997; Flueck 2000). Moreover, cervids respond to lack of food by progressively losing physical condition, subsequently having impaired reproductive success, becoming more susceptible to predation through more risk-taking (Creel and Christianson 2008), and eventually dying from predation, disease or starvation, the latter which can even occur during the growing season (Flueck and Smith-Flueck 1996). Given that this scenario applies to all cervids deprived of food, this type of organismal response is a maxim. Regardless, food deprivation due to artificial overpopulation resulting in predictable physiological responses hardly qualifies as "natural" self-regulation in cervids in the first place (Flueck 2000). All in all, it must be emphasized that cervids in intact ecosystems have not been shown to reach densities of high impact, and that D\&W characterized native deer as keystone species in cases where these became overabundant in artificial settings where they caused changes in ecosystems.

\section{Cervids introduced to southern Latin America}

Distribution of introduced deer in Argentina

South America has many native deer, but also a history of having introduced numerous exotic cervids. In Argentina, fallow deer occur in parts of closed forests and altitudes above tree line in the Andes and in adjacent open Patagonian grasslands (pers. observations). They also occur in the Provinces of Buenos Aires, Santa Fe, and La Pampa (Petrides 1975), all with ongoing hunting programs. Chital deer (Axis axis) had been introduced to the provinces of Buenos Aires, Santa Fe, Entre Rios, Neuquen, Rio Negro, and La Pampa (Petrides 1975). Although continuously hunted, Chital deer populations have risen to pest proportions in some provinces, interfering with livestock production. The largest area is invaded by red deer and includes several provinces (Neuquen, Rio Negro, Chubut, Mendoza, Salta, Jujuy, Tucuman, San Luis), and several other provinces have captive red deer (Buenos Aires, Entre Ríos, Corrientes, La Rioja, Santa Fe, Córdoba). The largest invaded area though is in Patagonia and has reached $>51,000 \mathrm{~km}^{2}$ actually occupied (Flueck et al. 2003a).
Future prospects for introduced red deer in southern Latin America

Once exotic cervids successfully adapt in an ample new environment, they likely end up remaining there, irrespective of professional opinions of scientists and managers and all the advanced technology available. In rare situations, such as islands, an eradication program might be justifiable and successful. However, managers have not been able to extirpate exotic ungulates in most countries, even NZ or Australia which have the most favorable opportunities (technically, economically, and politically). Southern Latin America has an area invaded by red deer about $85 \%$ the size of the area invaded in NZ (Nugent et al. 2001; Flueck et al. 2003b). Given the highly unconducive economical, technological and political conditions, eradicating red deer from areas invaded in southern Latin America was considered unfeasible by government officials: it was not a matter of not attempting as put forth by D\&W. Eldridge et al. (1980) suggested that the red deer invasion was unlikely to be stopped in Chile, and a national workshop came to the same conclusion for Argentina (Ramilo et al. 1986). Flueck et al. (2003b) estimated that the red deer distribution in Patagonia will reach $>$ three times the area invaded in NZ in the next 50 years due to a lack of barriers.

Relative impacts of introduced and native deer on forests in southern Latin America

Frequently, effects of exotic deer on ecosystems are quantified by analyzing forest structures. Veblen et al. (1989) studied effects of exotic deer on Argentine forest composition and regeneration by comparing vegetation on an island, where abundant exotic deer but no livestock lived, with a nearby peninsula which was free of exotic deer and livestock. High-density red deer and fallow deer on this forested island void of large predators affected vegetation dynamics as expected. Additionally, Veblen et al. (1992) looked at impact from exotic ruminants along a vegetation gradient in a National park, from Andean rain forests to xeric Patagonian grasslands. Deer and livestock in combination had significantly altered the floristic composition and stand structure along this gradient, as it was impossible to differentiate impact from deer 
versus livestock, as 56\% of national park areas are used by livestock (Simberloff et al. 2003).

D\&W suggested that impact from exotic deer should not be considered equivalent to that from native deer, based on exotic deer in Chile and Argentina having impacted native forests, at densities far exceeding those of native cervids. They cited Veblen et al. (1989, 1992), but native deer had been exterminated $>100$ years ago in both study areas which was long before the arrival of exotic deer. Also, neither study provided estimates of densities of native nor exotic deer, thereby invalidating these comparisons and conclusions. In addition, prior to the arrival of exotic deer, these areas had a history of native deer being regularly hunted by aborigines, widespread anthropogenic fires, as well as the presence of immense herds of post-Columbian feral livestock throughout the region, and heavy hunting by early settlers (Flueck and Smith-Flueck 1993, 2008). Moreover, scarce early historic data indicated wintering groups exceeding 100 huemul, large groups of early explorers feeding themselves for weeks on huemul, and in one area two thousand huemul kills per year were estimated, mainly to feed dogs, pigs and chicken (Iglesias 1965; Jiménez et al. 2008). Currently no native deer populations exist in areas similar to study areas used by Veblen et al. (1989, 1992), and comparisons to current densities of native deer living in remote refuge habitats would result in biased and spurious conclusions. In the common event of sympatric exotic deer and livestock, effects on forests cannot be differentiated (Veblen et al. 1992), and there is no data on impacts from historically more numerous native deer and guanaco, nor any data allowing a comparison of extant effects from exotic versus native deer.

Do introduced deer compete with native deer in southern Latin America?

Regarding diet and habitat overlap, competition for forage might be anticipated between native and introduced deer. Diaz and Smith-Flueck (2000) questioned this assumption and summarized how red deer has often been assumed to outcompete huemul, even being claimed responsible, in part, for recent declines of huemul, yet no examples have ever been documented (Jiménez et al. 2008). In contrast, huemul have disappeared in numerous areas lacking cattle, sheep, or exotic red deer (Smith-Flueck 2003).
D\&W reported high trophic overlap between red deer and huemul quoting Galende et al. (2005). Yet these authors studied only huemul diet based on merely five pellet groups for each of four seasons, and then made comparisons with red deer diet from another study on an island in a completely different environment (Relva and Caldiz 1998). Though unfounded, Galende et al. (2005) concluded that the "coexistence of these two cervids will produce interferences such as dietary displacement". Moreover, the one mayor food item-a single tree species - used by huemul in their study, was not only erroneously stated to be important in the red deer diet, but is absent in the area where red deer was studied years earlier (Relva and Caldiz 1998). As Galende et al. (2005) did not sample red deer, and certainly did not show the existence of dietary competition or displacement between the two species, it is prudent to ignore their affirmative statement that sympatry of both cervids will produce interference such as dietary displacement: there is simply no data to support it.

It is unfortunate that Galende et al. (2005) did not study the diet of sympatric red deer in their huemul study area, given the important conservation implications and the area having been designated as Critical Area for huemul in that national park. The minimum size of that huemul herd was estimated at five huemul (Pastore and Vila 2003). Meanwhile red deer, with $20 \%$ more pellet groups, required Galende et al. (2005) to distinguish pellets by hair analysis. Moreover, the commonly cooccurring livestock in that same part of the national park could also have been sampled. Livestock, not red deer, interact with many huemul herds: this national park has $56 \%$ of its total area covered by livestock (Simberloff et al. 2003). Furthermore, Pastore and Vila (2003) measured signs along transects in this same study area and showed that livestock signs surpassed those of huemul by an impressive factor of 25.2 (horse, cattle and sheep were 12.8, 9.6 and 2.8 times more common than huemul, respectively). Similarly, Martínez (2008) described the other Critical Area for huemul in another national park, where five settlers with old grazing rights occupy practically the whole unfenced area with their livestock. The estimated 14 huemul (Vila et al. 2009) share the space with 377 large herbivores (mainly cattle) and 360 sheep and goats. The livestock estimates were provided by the settlers 
and likely are underestimates (Serret et al. 1994). Space, however, is not shared equally and livestock have nearly exclusive use of the winter range, whereas huemul occur principally in areas not used by cattle on the summer range, amounting to about $10 \%$ of the Critical Area. Thus, huemul are forced to remain on summer ranges nearly all year, and only occasionally are they seen in lower areas. Martínez (2008) found that the settlers generally consider any measure limiting their livestock raising as unacceptable, and that the park managers can neither eliminate nor regulate livestock production, unless they achieve that settlers understand that the survival of these last huemul depends to a large degree on their use of the land with livestock. To overcome this hurdle, the study recommended: to hold workshops with the settlers to teach them to recognize plants; to fence areas to allow management and keep feral livestock out; to mark and tag livestock; to eliminate unneeded dogs and implement the park dog ordinance; and to get the agreement of settlers to reduce the amount of livestock. It indicates why the park administration has not been able to eliminate illegal and legal livestock from the park because avoiding conflict with local settlers takes precedence, and no funds are available to fence large tracks of national park territories. Thus, a convenient culprit for the huemul predicament is non-controversial red deer, for they have no owner, and consequently, limited park funds may be used to send employees to such areas to try to stop their spread and control densities through hunting (APN 2006).

D\&W stated that the assumption of low huemul density in habitats with high densities of introduced herbivores precluding food limitation, lacks substance. In actuality they misread the source which stated that "nutritional constraints for current lowdensity huemul appear improbable (except winter range inaccessibility), considering equivalent habitats support high densities of exotic herbivores" (Flueck and Smith-Flueck 2006a). Thus, if equivalent areas produce $3,000-5,000 \mathrm{~kg} / \mathrm{km}^{2}$ of exotic ruminant biomass, there should be enough forage to support low density huemul (which are not known to occur sympatrically with exotics at high density), which is supported by very high marrow fat contents measured in huemul (Smith-Flueck and Flueck 2001). Krieg (1940) also suggested that forage, which supported a large quantity of exotic herbivores with superb body development, could not explain the absence of huemul. While some plants are certainly utilized by red deer, these are also heavily browsed by most other ungulates. It is a rare situation to have red deer as the sole large herbivore in a habitat as noted by Veblen et al. (1992). In fact, most remaining huemul populations are foremost exposed to impact from livestock, and only in rare cases are red deer present (Smith-Flueck 2003, Flueck and Smith-Flueck 2006a, Martínez 2008). With huemul, studies on effects from alien ruminants should emphasize domestic livestock rather than exotic cervids. The attention on exotic cervids on the other hand should be directed at the ongoing invasion of mainly red deer.

Does the presence of introduced deer increase predation on native South American deer?

Prey species can sometimes indirectly depress each other by increasing the abundance of a shared natural predator, an effect called apparent competition (Holt 1977), which could occur if exotic deer cause higher predation rates on native deer. In discussing apparent competition, D\&W relied solely on examples from South America. Based on Novaro et al. (2000), where biomass of introduced herbivores greatly exceeded that of native prey in Patagonia, D\&W suggested that exotic alternative prey likely resulted in increased densities of native predators, which in turn could then adversely affect native huemul and pudu (Pudu $p u d u)$. First, neither huemul nor pudu have occurred in modern times in this part of Patagonia, let alone in that study area, and some will argue that they never existed in that type of Patagonian habitat in the first place (see Redford and Eisenberg 1992, Webb 1992). D\&W assumed incorrectly that huemul and pudu, being found in Patagonia, must be living in habitats like the one in Novaro's study.

Next, to back their argument, but not considering the diversity of habitat types throughout Patagonia, they erroneously selected a generalized statement from Novaro et al., where reference is made to low densities of native herbivores in Argentine Patagonia. This statement misrepresented the actual overall situation for although guanaco was the only native prey of their steppe site, at only 0.67 animals $/ \mathrm{km}^{2}$, guanaco densities in other Patagonian regions are up to 7.6 times higher (Baldi et al. 2001; Sarno and Franklin 1999). Thus Novaro et al. (2000) should 
only have been referring to their site, not generalizing to all of Patagonia, but D\&W failed to pick up on this oversight. Additionally, if the impressive exotic herbivore biomass of $3,015 \mathrm{~kg} / \mathrm{km}^{2}$ did indeed increase predator density, Novaro et al. (2000) found no signs of predation on guanaco making up only $2 \%$ of prey biomass. Rather they concluded that predators selected their prey according to catchability, i.e. focused on the most common species, which was not native guanaco. Since guanaco was not preyed upon, results by Novaro et al. (2000) then are in sharp contrast to D\&W's suggestion that nonnative prey cause an increased predator density to the point where native prey may be adversely affected. Moreover, given that Novaro et al. (2000) provided no data on predator density nor any information allowing to make a link to native huemul or pudu, the assertion that "there is evidence that densities of native predators of huemul and pudu are locally elevated by introduced prey", by citing Novaro et al. (2000), was not justified.

To further back their argument, D\&W used a study by Franklin et al. (1999) for their own statement that "introduced sheep are now an important prey of puma”. However, Franklin et al. (1999) reported that prey items consisted of 51\% European hares (Lepus europeaus), $23 \%$ guanacos and only 5\% sheep, concluding that the puma's most important prey item by biomass was guanaco whereas sheep was not important. Furthermore, the suggestion by D\&W that availability of livestock, wild boars (Sus scrofa) and hares is more likely to affect puma predation on huemul than availability of red deer is misplaced: there are neither wild boars nor red deer in that area, and sheep was not an important source of food for puma (Franklin et al. 1999). Thus, whereas Novaro et al. (2000) reported zero use by puma of native guanaco which were at a density 18.5 times lower than at the site in Franklin et al. (1999), these latter authors found in contrast the puma diet containing $59 \%$ guanaco by weight.

It would be misleading to ignore that Franklin et al. (1999) reported a guanaco population increase between 1975 and 1988 from 97 to 1276 animals in their study area, in the presence of a high density of six puma/100 $\mathrm{km}^{2}$. A population increasing 13.2 fold hardly translates into some negative effect from puma predation induced by exotic prey. It shows instead that even in presence of exotic prey species, a possibly growing puma population was not preventing guanaco from also increasing in numbers. An important parallel observation can be made regarding huemul. First, during this puma study in 1986-1988, Franklin et al. (1999) made no mention of huemul. Second, the area of Torres del Paine is the only place known to have a growing huemul population; during the last 2 years huemul have expanded towards the drier eastern grassland areas where the guanaco abound (Guineo et al. 2008). Thus, both native ungulates are increasing in presence of a certainly healthy puma population. The assertion that apparent competition by exotic deer or other exotic prey via increasing predation pressure on native cervids exists, is not supported by the South American case presented by $\mathrm{D} \& \mathrm{~W}$, and both cited studies actually demonstrated the opposite.

The role of foxes (Pseudalopex culpaeus) in huemul dynamics, with or without presence of exotic prey, can only be resolved through local quantitative studies. Work cited by D\&W that foxes predate on huemul, did not study foxes and only suggested that this might be occurring. Similarly, stating that the density of foxes was elevated due to introduced hares, cannot be deduced from the cited source which commented only that foxes were common, probably because of abundant hares, as neither foxes nor hares were studied. Additionally, wild boars commonly prey on domestic lambs and adult sheep in Patagonia. Also being known to prey on cervid neonates (Pavlov 1981; Seward et al. 2004), they too would need to be considered as potential predators of huemul (Diaz and Smith-Flueck 2000). Lastly, domestic dogs have been considered an important mortality factor in several huemul herds, killing up to $36 \%$ of fawns (Jiménez et al. 2008), which adds further complexity to predation on huemul.

\section{Discussion}

Categorizing cervids according to narrow ecological characteristics has inherent limitations. The magnitude of plasticity of a species is most important, for this inherent ability to produce a range of potential responses plays a major role in the outcome of organismic interactions (Agrawal 2001). Regarding impact of exotic deer on native South American deer, D\&W considered the two sole native species of 
Hippocamelus to be adapted to ecotonal and forest habitats of the Andes. To the contrary, the northern $H$. antisensis are considered neither a forest nor an ecotone dwelling species, but occurs mainly in alpine wet or dry grassland at elevations of 2,500-5,200 m (Wemmer 1998). Currently, huemul are found mainly in forested areas, having been eliminated from open grassland landscapes especially east of the Andes (Díaz 1993). Besides several patent historical records of huemul occurring hundreds of kilometers from forests (reviewed in Díaz 1993), a few populations still occur today in ecotonal grasslands, in sympatry with guanaco. Darwin's crew shot huemul regularly near the Atlantic coast (Fig. 1), far from forests (Diaz and Smith-Flueck 2000). Furthermore, Frid (1994, 2001) found high densities of huemul in periglacial areas in remote southern coasts of Chile, with twice as much use of open grasslands than forests in absence of livestock and permanent settlers. Thus, habitat breadth of huemul is similar to Odocoileus based on historical records and data from coastal Chile, but this is not evident if considering only forested refuge areas, which are most commonly occupied nowadays.

Effects of overabundant deer on ecosystems do not fall along the dichotomy of native versus exotic deer. Overabundant native deer occur when anthropogenic activities disrupt predator communities or modify pristine habitat by changing nutrient cycles or habitat structure through logging and agriculture. Frequently, ensuing intensified interactions with certain ecosystem components are considered undesirable. Exotic deer also become overabundant if introduced to areas

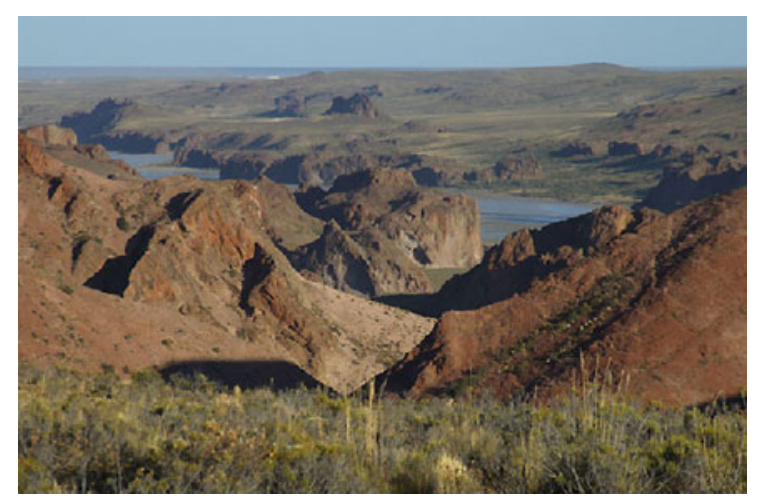

Fig. 1 Landscape by Port Desire at Atlantic coast, where Darwin's crew hunted huemul for subsistence (S 47 44', W 65 $\left.54^{\prime}\right)$ with inadequate predator communities, and furthermore, even if kept artificially at low densities, their effects on native organisms may still be undesirable. Nonetheless, overabundant deer, not being rare in occurrence, should not be called keystone species as was done in D\&W's review. Being abundant, they certainly will have exceedingly strong interactions in ecosystems and will exert directional changes in numerous facets. Many disturbed populations of native deer currently represent problems much closer to those of exotic deer populations than to those of native deer in near-pristine conditions (McShea et al. 1997; Cote et al. 2004; Stockton et al. 2005).

Although diets of allopatric red deer and huemul have similarities, actual food preferences by themselves are weak measures to discern impacts from exotic ruminants. For deer, food preference is a highly plastic trait as it changes according to plant density, intraspecific and interspecific densities, disturbances including predation, or different energetic costs: it is by no means static (Nudds 1980; Challies 1990). Whereas individual studies based on certain habitats or seasons show huemul to have a narrow diet suggestive of a concentrate selector (Frid 1994; Smith-Flueck 2003; Galende et al. 2005), overall dietary breadth across studies is rather large and includes at least 145 plant species (Aldridge et al. 2007; Guineo et al. 2008). Furthermore, during the 1930s huemul lived several years in the subtropical Buenos Aires Zoo, under a diet of plants nonexistent in their native range, which was $>2,000 \mathrm{~km}$ further south (Flueck and Smith-Flueck 2006a). To understand huemul, their feeding behavior in habitat types where they were exterminated by man, would also have to be determined. Successful cervids are those in any regional habitat allowing a stable population, with additional habitat types to serve as sink areas. As the classification used by D\&W for Hippocamelus does not coincide with known facts, it would lead to erroneous conclusions.

Regardless of interest in exotic deer affecting huemul, most of the remaining huemul populations are foremost exposed to livestock, and only in exceptional cases do red deer cooccur. At present, interest should be channeled towards domestic livestock rather than exotic cervids. Important impacts on native deer would be indicated by exotic herbivores causing a negative population growth rate in native deer. Regarding livestock, some huemul herds have 
persisted in presence of cattle production lasting more than 110 years (Jiménez et al. 2008), likely because associated human and dog predation was absent or controlled.

The case made for apparent competition via predation, based on two studies from Patagonia, had major flaws. The construct is supposedly valid for Patagonia, but relied on data coming from livestock ranches in dry grasslands, with native guanaco occurring at very low density as the sole native prey. Conclusions drawn by $\mathrm{D} \& \mathrm{~W}$ that introduced prey are resulting in increased predation rates on native ungulates was not supported. In fact, both studies showed the opposite. Moreover, the high-density puma population in Franklin et al. (1999) could prevent neither the increase of guanaco $>13$-fold, nor huemul populations expanding into these sites. Lastly, neither of these two studies had looked at native deer nor even mentioned it in their study areas, nor were trend data of predator densities provided. Considering all this, the conclusion that apparent competition between introduced cervids and other exotic prey and native deer may be occurring is unfounded.

The potential for apparent competition via a puma, since it is the only large Patagonian predator, merits further considerations. Is it possible that exotic deer allow puma densities to increase and thereby increase predation pressure on huemul and pudu? Puma are highly plastic, with diets ranging from $>99 \%$ ungulates (Ross et al. 1997) to $>96 \%$ lagomorphs (Rau et al. 1991), and it even includes swans, rheas and monkeys (Ludwig et al. 2007). As elsewhere, the diet of Patagonian puma depends on prey availability and vulnerability (Iriarte et al. 1990; Novaro et al. 2000). For instance, increasing seasonal hare densities induced a concomitant higher intake by puma, and when guanaco population doubled between 1982 and 1988, guanaco increased from 9 to $30 \%$ in the diet (Iriarte et al. 1990).

On the other hand, puma facing prey reductions respond with population declines, usually following a lag time (Pierce et al. 2000; Laundre et al. 2007). Thus, when deer as primary prey declined, puma numbers subsequently dropped without negatively affecting alternative prey species which could not prevent the puma's decline (Laundre et al. 2007). When this deer population reached its lowest level, the puma population actually peaked, and then would have had their biggest impact: yet puma did not cause extinction of deer, instead declined in numbers and deer rebounded. Hence, a substantially reduced deer population recovered even with puma still at high density, and predation by pumas merely delayed deer recovery by $2-3$ years (Laundre et al. 2006). Similarly, Hornocker (1970) found that cervids increased even with the highest puma density known, equivalent to high densities in southern Chile (Franklin et al. 1999). Hornocker concluded that puma were thus not able to prevent deer from increasing, which Flueck et al. (2005) confirmed regarding puma and red deer in Patagonia, and Guineo et al. (2008) regarding puma and huemul. As no cases of deer being regulated by puma as sole large predator are known, Smith-Flueck and Flueck (2001) cautioned if puma may have regulated huemul.

For a generalist like puma, recruitment and survivorship are likely to be related to total food supply, not just the density of one particular prey species (Pech et al. 1995). Based on puma energetics (Laundre 2005), actual predation rates (Cooley et al. 2008; Laundre 2008), and adjusting for larger body size of Patagonian puma (Franklin et al. 1999), an adult puma would need to consume about 65 huemul per year as primary prey. There are 101 herds recognized for the $1,000-1,500$ remaining huemul, but $60 \%$ of the herds amount to only 10-20 individuals each (Vila et al. 2006). Thus, the persistence of these small herds indicates that currently huemul could not be a primary prey for puma. It also raises the question, if pumas are the only large predator, why do huemul not recover like other cervids occurring in essentially single-prey, single-puma predator systems (Brown et al. 1999; Hornocker 1970)?

Effects of puma on bighorn sheep (Ovis canadensis) may shed some light as today's bighorn herds, like the huemul, are generally small and isolated. Fortunately for bighorns, most puma, even when at very high densities, prefer to hunt cervids and smaller prey over bighorns. However, sometimes a rare puma will selectively hunt bighorns, and in one case an individual puma, after reaching old age, was found to switch from deer to bighorns (Hornocker 1970; FestaBianchet et al. 2006; Pelletier et al. 2006). It only takes a few puma focusing on reduced herds of bighorns to cause population declines, a phenomenon shown to have occurred in three small herds at least once over 2-3 decades (Festa-Bianchet et al. 2006), 
who suggested that it could result in local extinctions. Predator-prey equilibria may then only function at large geographical and temporal scales through recolonizations. In such cases, puma predation on bighorns varies greatly, as Ross et al. (1997) found puma to kill $0-13 \%$ of different bighorn herds, and to cause $0-57 \%$ of over-winter mortality. However, although Wehausen (1996) documented puma reducing a bighorn herd to eight ewes, what is more important, 3 years later, when predation pressure abated on this herd, the bighorn population increased annually at $15 \%$ for the next 3 years. Moreover, in New Mexico in presence of puma, two of 3 alpine bighorn herds passed carrying capacity and required trapping and removal to keep their numbers down (Hacker et al. 2000). Based on reviewing small bighorn herds, Berger (1990) concluded that the rapid loss of herds was unlikely caused by predation, and specialized puma predation appears to be an infrequent event in bighorns.

Given that most huemul herds have $<20$ individuals, it is instructive that to date no evidence shows local extinctions due to puma (Guineo et al. 2008). Furthermore, all huemul herds are below the minimal herd size (estimated at 125 individuals) to be able to persist under the scenario of specialized puma predation as suggested by Festa-Bianchet et al. (2006), indicating that such specialized puma predation does not occur with huemul. Huemul from reduced herds must regularly be able to find refuge from predation or, if their density becomes low, alternative prey may be sufficiently abundant to deflect predation pressure and they essentially may be only a casual by-catch (see Pech et al. 1995). Persistence of small huemul herds may also result from differences in predatoravoidance behavior producing a relatively invulnerable class of animals. For instance, Dingemanse and Réale (2005) showed that ungulate prey subjected to increased puma predation resulted in bolder prey as these had increased survival and reproductive rates. It was suggested that bold individuals are more prone to inspect predators which deters predators, and bold individuals are thus less likely to be attacked by predators than shy individuals. Boldness has been related to aggressiveness, which also can lead to increased survival as evidenced by white-tailed deer killing wolves and a single deer standing off three wolves (Nelson and Mech 1993), or a female red deer defeating a puma (Flueck 2004). Behavior then buffers the system where the presence of more predators makes it harder for each individual predator to capture prey because of increasing prey wariness. Puma rarely harvest more than one prey animal and thus deplete a food patch like a local herd of mule deer (Brown et al. 1999) by frightening prey rather than by actually killing prey, as deer become either warier and harder to catch or they vacate the area for another patch. Such avoidance behavior is documented for huemul in southern Chile where groups left an area upon noting a puma (G. Garay, pers. comm.). Similarly, huemul flight distance towards humans and dogs can increase over time and differs among areas, and they have been documented to escape from exotic canids like dogs (Jiménez et al. 2008). Such predator- prey systems may generate a very robust and resilient persistence of prey and predator. White et al. (2006) did a comprehensive review of the invasion biology literature for the occurrence of apparent competition, without finding examples of exotic deer causing it via predation effects on native deer.

Given that guanaco and huemul numbers have increased in the presence of exotic prey and a very high density puma population, that huemul have shown plasticity through predator-avoidance behavior, that they are persisting in puma territory even in presence of exotic prey despite very reduced herd sizes, and that past local extinctions occurred in absence of exotic prey, indicate that apparent competition via puma is an unlikely explanation for this species' failure to recover. Supporting data certainly is nonexistent. On the other hand, I believe that puma predation, even if only occasional as an incidental catch, is a stochastic event which could result in local extinctions of severely reduced herds. Unfortunately, $60 \%$ of the herds consist of only 10-20 huemul, which are often isolates such as the last population in central Chile is over $400 \mathrm{~km}$ from the next herd (Jiménez et al. 2008).

\section{Conclusions}

Based on their global review of impacts from exotic deer on ecosystems and on native deer, D\&W suggested that the scale and generality of detrimental impacts have not been widely recognized. To make the case, examples from South American, based on a few studies from particular sites, were used and 
extrapolated as valid for Patagonia. Effects of exotics on vegetation stemmed from study sites where huemul had been exterminated and comparing current effects from exotic versus native deer is invalid. The suggestion that red deer likely affect huemul through exploitation competition stemmed from studies showing trophic overlap, however, none of these included sympatric situations or measures of huemul herd performance. Furthermore, the history of red deer in eight sites formerly used by huemul showed that these went extinct in half the sites before arrival of red deer. Possible overlap in the remaining cases would have been for short periods, and the initially low density of red deer unlikely caused huemul extinction, less so if considering the prevailing presence of settlers and their livestock (Smith-Flueck 2003). As most remaining huemul populations are not exposed to exotic deer, but rather to domestic livestock including feral populations, studies on plant-herbivore interactions would need to include all present ungulates, particularly the omnipresent cattle.

Apparent competition was suggested to occur between exotic and native South American deer. However, the case was based on two studies which not only contradicted this claim, but neither one included native deer for they did not occur in those study areas, and it clearly does not stand up as a global example for the existence of apparent competition among cervids. Vazquez (2002) cautioned that it is not possible to test whether the decline of huemul throughout its range was caused by introduced ungulates through mechanisms like apparent or exploitation competition, because the few studies about introduced herbivores came from few locations, and although tempting to extrapolate these effects to entire Patagonia, it would be risky to do so. In contrast, a more likely type of apparent competition is from omnipresent livestock through increased human and dog presence with common huemul kills, as proposed by Frid (2001).

Comparing data from native and exotic deer would benefit if discussed in relation to modified landscapes and exterminated predators. It is well known that intact predator communities not only exert a regulatory function over cervid populations, but they also modify prey species behavior and habitat use. Thus, relationships between different prey species, including competition, are strongly linked to the presence of predators. For generalizations to be valid, comparisons need to be controlled for effects of landscape modifications and incompleteness of predator communities, as these may mask the fundamental causal relationships under natural conditions.

Studies about interactions between exotic and native deer need to address the plasticity of various characteristics exhibited by involved species, rather than relying on broad classifications. Persistent multispecies assemblages of herbivores and predators are the rule rather than the exception and relate undoubtedly to adaptive plasticity. For little-known species, not only is basic information regarding their plasticity lacking, but conditions prior to human-induced ecosystem modifications might have been completely different. Ignoring historic settings and relying on limited modern data thus could lead to spurious conclusions and generalizations. If little-known species are to be used, explicit reference to uncertainties in the original data and conclusions is essential. The example from South America also indicates the need to consider the herbivore and predator communities in their entirety. In the case of huemul, the role of predation is not only determined by puma, but likely includes foxes, wild boars, owned and feral dogs, and illegal hunting. Focusing on exotic deer is misleading if native huemul are foremost exposed to impacts from free-ranging livestock, both managed and feral. The unsupported emphasis on blaming red deer for the huemul's decline is partially due to the general inability to rid areas, including those protected like national parks, of livestock due to sociopolitics, thus using red deer instead as the culprit. Consequently, Frid (2001) urged that cattle and other livestock be removed from known huemul hotspots, including national parks. Resources should also be allocated to long-term monitoring of huemul-exotic deer interactions as exotic deer populations continue to expand (Flueck et al. 2003b).

Most huemul herds across their whole remaining distribution exist far from exotic deer, yet they are not recovering, or are actually declining. Several of the proposed causes for lacking recoveries might be locally important, but like in the case of exotic deer, have been shown not to explain the general situation. Recently, however, a testable ecological hypothesis has been suggested as a proximate cause for the general absence of huemul recovery. Areas currently used by huemul are known to be marginal or deficient in several trace minerals, and combined with the 
elimination of traditional use of more fertile portions of the range (valley bottoms and eastern lowlands), huemul frequently survives in isolated refuge areas resulting in low recruitment rates (Flueck and SmithFlueck 2006b). In addition, the high incidence of osteological disease in several populations points to such nutritional problems (Flueck and Smith-Flueck 2008).

Acknowledgments I thank Andrea Taylor, Associate Editor for Wildlife Research, for constructive criticism during four revisions involving five additional anonymous reviewers, which substantially improved the paper, although in the end it was declined. I also thank Jo Anne Smith-Flueck and one anonymous reviewer for this journal for their many valuable comments, and Alejandro Frid who constructively reviewed every version. This manuscript was made possible through support from various institutions for many years of field work on huemul and red deer, and through help of numerous collaborators and volunteers. The work would not have been possible without the generous support from El Retorno, Bariloche and Cyon GmbH, Switzerland.

\section{References}

Agrawal AA (2001) Phenotypic plasticity in the interactions and evolution of species. Science 294:321-326

Aldridge D, Lopez R, Saucedo C, Vila AR (2007) Los ultimos senderos del huemul, Fundación Hiunay, Chile

Altendorf KB, Laundre JW, Lopez Gonzalez CA, Brown JS (2001) Assessing effects of predation risk on foraging behavior of mule deer. J Mammal 82:430-439

APN (Adminstración de Parques Nacionales Argentina) (2006) 5ta Reunión binacional Argentino-Chilena sobre estrategías de conservación del huemul, Bariloche, Argentina

Baldi R, Albon SD, Elston DA (2001) Guanacos and sheep: evidence for continuing competition in arid Patagonia. Oecol 129:561-570

Berger J (1990) Persistence of different-sized populations: an empirical assessment of rapid extinctions in bighorn sheep. Cons Biol 4:91-98

Berger J, Stacey PD, Bellis L, Johnson MP (2001) A mammalian predator-prey imbalance: grizzly bear and wolf extinction affect avian neotropical migrants. Ecol Appl 11:947-960

Beschta RL, Ripple WJ (2009) Large predators and trophic cascades in terrestrial ecosystems of the western United States. Biol Conserv 142:2401-2414

Breitenmoser U, Haller H (1993) Patterns of predation by reintroduced European lynx in the Swiss Alps. J Wildl Manage 57:135-144

Brown JS, Gurung M, Laundre JW (1999) The ecology of fear: optimal foraging, game theory, and trophic interactions. J Mammal 80:385-399

Challies CN (1990) Red deer. In: King CM (ed) The handbook of New Zealand mammals. Oxford University Press, Oxford, pp 436-458
Cooley HS, Robinson HS, Wielgus RB, Lambert CS (2008) Cougar prey selection in a white-tailed deer and mule deer community. J Wildl Manage 72:99-106

Cote SD, Tremblay J, Dussault C, Waller DM, Rooney TP (2004) Ecological impacts of deer overabundance. Annu Rev Ecol Evol Syst 35:113-147

Creel S, Christianson D (2008) Relationships between direct predation and risk effects. TREE 23:194-201

Díaz NI (1993) Changes in the range distribution of Hippocamelus bisulcus in Patagonia. Zeits Säugetierkunde 58:344-351

Díaz NI, Smith-Flueck J (2000) The Patagonian huemul. A mysterious deer on the brink of extinction. Literature of Latin America, Buenos Aires

Dingemanse NJ, Réale D (2005) Natural selection and animal personality. Behav 142:1165-1190

Dolman PM, Wäber K (2008) Ecosystem and competition impacts of introduced deer. Wildl Res 35:202-214

Eldridge WD, Pacheco NV, Courtin SL (1980) Preferencias de habitat y patrones de actividad del ciervo exotico en el sur de Chile. Medio Ambiente (Chile) 4:56-74

Festa-Bianchet M, Coulson T, Gaillard JM, Hogg JT, Pelletier F (2006) Stochastic predation events and population persistence in bighorn sheep. Proc Roy Soc London, Series B 273:1537-1543

Flueck WT (2000) Population regulation in large northern herbivores: evolution, thermodynamics, and large predators. E J Wildl Res 46:139-166

Flueck WT (2004) Observations of Interactions between puma, Puma concolor, and introduced European red deer, Cervus elaphus, in Patagonia. Can Field-Nat 118: 132-134

Flueck WT, Smith-Flueck JM (1993) Über das in Argentinien angesiedelte Rotwild (Cervus elaphus, L., 1758): Verbreitung und Tendenzen. Zeits Jagdwissenschaft 39: 153-160

Flueck WT, Smith-Flueck JM (1996) Can energy deficiency cause deer die-offs on northern mountain ranges? an exploratory analysis of Odocoileus hemionus. Zeits Jagdwissenschaft 42:85-96

Flueck WT, Smith-Flueck JM (2006a) Predicaments of endangered huemul deer, Hippocamelus bisulcus, in Argentina: a review. E J Wildl Res 52:69-80

Flueck WT, Smith-Flueck JM (2006b) Why the Patagonian huemul deer in Argentina fails to recover: An ecological hypothesis. In: Bartos L, Dusek A, Kotrba R, Bartosova J (eds) Advances in deer biology: deer in a changing world. Research Institute of Animal Production, Praha, Czech Republic, pp 181-185

Flueck WT, Smith-Flueck JM (2008) Age-independent osteopathology in skeletons of a south American cervid, the Patagonian huemul (Hippocamelus bisulcus). J Wildl Dis 44:636-648

Flueck WT, Smith-Flueck JM, Naumann CM (2003a) The current distribution of red deer (Cervus elaphus) in southern Latin America. E J Wildl Res 49:112-119

Flueck WT, Smith-Flueck JM, Naumann CM (2003b) The current and future extent of the red deer invasion in Patagonia. In: Sutherland O (ed) 3rd international wildlife management conference. Landcare Research, Christchurch, p 407 
Flueck WT, Smith-Flueck JM, Bonino NA (2005) A preliminary analysis of cause-specific and capture-related mortality, and survival of adult red deer in northwestern Patagonia. Ecol Austral 15:23-30

Franklin WL, Johnson WE, Sarno RJ, Iriarte JA (1999) Ecology of the Patagonia puma Felis concolor patagonica in southern Chile. Biol Conserv 90:33-40

Frid A (1994) Observations on habitat use and social organisation of a huemul (Hippocamelus bisulcus) coastal population in Chile. Biol Conserv 67:13-19

Frid A (2001) Habitat use by the endangered huemul (Hippocamelus bisculcus): cattle, snow, and the problem of multiple causes. Biol Conserv 100:261-267

Galende G, Ramilo E, Beati A (2005) Diet of huemul (Hippocamelus bisulcus) in Nahuel Huapi National Park, Argentina. Studies Neotrop Fauna Environ 40:1-5

Guineo P, Guineo Garay R, Garay G (2008) Conociendo al huemul de Torres del Paine. La Prensa Austral, Punta Arenas, Chile

Hacker WD, Rominger EM, Dunn WC, Velasquez TG (2000) Management options for rocky mountain bighorn sheep populations at carrying capacity. In: Transactions of the 2nd North American wild sheep conference, Reno, Nevada, p 133

Haller H (2002) Der Rothirsch im Schweizerischen Nationalpark und dessen Umgebung. Eine alpine Population von Cervus elaphus zeitlich und räumlich dokumentiert. Nationalpark-Forschung Schweiz 91:1-144

Henke SE, Bryant FC (1999) Effects of coyote removal on the faunal community in western Texas. J Wildl Manage 63:1066-1081

Holt RD (1977) Predation, apparent competition, and the structure of prey communities. Theor Pop Biol 12:197-229

Hornocker MG (1970) An analysis of mountain lion predation upon mule deer and elk in the Idaho primitive area. Wildl Monogr 21:1-39

Iglesias RE (1965) El huemul. La Montaña (Argentina) 7: 26-28

Iriarte JA, Franklin WL, Johnson WE, Redford KH (1990) Biogeographic variation of food habits and body size of the American puma. Oecol 85:185-190

Jedrzejewski B, Jedrzejewski W, Bunevich AN, Milkowski L, Krasinski ZA (1997) Factors shaping population densities and increase rates of ungulates in Bialowieza Primeval Forest (Poland and Belarus) in the 19th and 20th centuries. Acta Theriol 42:399-451

Jiménez J, Guineo G, Corti P, Smith JA, Flueck W, Vila A, Gizejewski Z, Gill R, McShea B, Geist V (2008) Hippocamelus bisulcus. In: 2008 IUCN Red List of Threatened Species, IUCN, Gland, Switzerland

King CM (1990) The handbook of New Zealand mammals. Oxford University Press, Oxford

Krieg H (1940) Als Zoologe in Steppen und Wäldern Patagoniens. J.F. Lehmanns Verlag, München

Laundre JW (2005) Puma energetics: a recalculation. J Wildl Manage 69:723-732

Laundre JW (2008) Summer predation rates on ungulate prey by a large keystone predator: how many ungulates does a large predator kill? J Zool 275:341-348

Laundre JW, Hernandez L, Clark SG (2006) Impact of puma predation on the decline and recovery of a mule deer population in southeastern Idaho. Can J Zool 84: $1555-1565$

Laundre JW, Hernandez L, Clark SG (2007) Numerical and demographic responses of pumas to changes in prey abundance: testing current predictions. J Wildl Manage 71:345-355

Leader-Williams N (1988) Reindeer on South Georgia. The ecology of an introduced population. Cambridge University Press, Cambridge

Lever C (1985) Naturalized mammals of the world. Longman Inc, New York

Ludwig G, Aguiar L, Miranda J, Teixeira G, Svoboda W et al (2007) Cougar predation on black-and-gold howlers on Mutum Island, southern Brazil. Intern J Primatol 28:39-46

Martínez LV (2008) Evaluación del espacio para la ganadería extensiva sustentable y la conservación del Huemul (Hippocamelus bisulcus), en el Parque Nacional Los Alerces, Provincia de Chubut, Argentina. APRONA Bol Cient (Argentina) 41:45-67

Masseti M, Mertzanidou D (2008) Dama dama. In: 2008 IUCN red list of threatened species, IUCN, Gland, Switzerland

McShea WJ, Underwood HB, Rappole JH (1997) The science of overabundance: deer ecology and population management. Smithsonian Inst. Press, Washington

Messier F, Crete M (1985) Moose-wolf dynamics and the natural regulation of moose populations. Oecol 65: 503-512

Mills LS, Soule ME, Doak DF (1993) The keystone-species concept in ecology and conservation. Bioscience 43: 219-224

Nelson ME, Mech LD (1993) A single deer stands-off three wolves. Am MidI Nat 131:207-208

Novaro AJ, Funes MC, Walker RS (2000) Ecological extinction of native prey of a carnivore assemblage in Argentine Patagonia. Biol Cons 92:25-33

Nudds TD (1980) Forage preference: theoretical considerations of diet selection by deer. J Wildl Manage 44:735-740

Nugent G, Fraser KW, Asher GW, Tustin KG (2001) Advances in New Zealand mammalogy 1990-2000: deer. J Roy Soc NZ 31:263-298

Paine RT (1966) Food web complexity and species diversity. Am Naturalist 100:65-75

Pastore H, Vila A (2003) Situación de la población de huemules en la jurisdicción de la Seccional Nirihuau, Parque Nacional Nahuel Huapi. Fundación Vida Silvestre Argentina and Wildlife Conservation Society, Final Report 2000-2002, pp 1-27

Pavlov PM (1981) Feral pigs-ungulate predators. NZ J Ecol 4:132-133

Payton IJ, Fenner M, Lee WG (2002) Keystone species: the concept and its relevance for conservation management in New Zealand. Sci Conserv 203:1-29

Pech RP, Sinclair ARE, Newsome AE (1995) Predation models for primary and secondary prey species. Wildl Res 22: 55-64

Pelletier F, Gendreau T, Feder C (2006) Behavioural reactions of bighorn sheep (Ovis canadensis) to cougar (Puma concolor) attacks. Mammalia 70:160-162

Petrides GA (1975) The importance of wild ungulates into Latin America, with remarks on their environmental effects. Environ Conserv 2:47-51 
Pierce BM, Bleich VC, Bowyer RT (2000) Social organization of mountain lions: does a land-tenure system regulate population size? Ecol 81:1533-1543

Pierce BM, Bowyer RT, Bleich VC (2004) Habitat selection by mule deer: forage benefits or risk of predation? J Wildl Manage 68:533-541

Pyare S, Berger J (2003) Beyond demography and delisting: ecological recovery for Yellowstone's grizzly bears and wolves. Biol Conserv 113:63-73

Ramilo E, Martin C, Chehébar C (1986) Taller sobre manejo del ciervo colorado y jabalí Europeo en jurisdiccion de la Administración de Parques Nacionales. Ministerio de Economía, Secretaría de Agricultura, Ganadería y Pesca, Administración de Parques Nacionales de Argentina

Rau JR, Tillería MS, Martínez DR, Muñoz AH (1991) Dieta de Felis concolor (Carnivora: Felidae) en áreas silvestres protegidas del sur de Chile. Rev Chilena Hist Nat 64: 139-144

Redford KH, Eisenberg JF (1992) Mammals of the Neotropics: The Southern Cone. Volume 2. Chile, Argentina, Uruguay, Paraguay, The University of Chicago Press, Chicago and London

Relva MA, Caldiz M (1998) Seasonal diet composition of exotic deer in Isla Victoria, Nahuel Huapi National Park, Argentina. Gayana Zool 62:101-108

Ripple WJ, Beschta RL (2008) Trophic cascades involving cougar, mule deer, and black oaks in Yosemite National Park. Biol Conserv 141:1249-1256

Ross PI, Jalkotzy MG, Festa-Bianchet M (1997) Cougar predation on bighorn sheep in southwestern Alberta during winter. Can J Zool 75:771-775

Sarno RJ, Franklin WL (1999) Population density and annual variation in birth mass of guanacos in southern Chile. J Mammal 80:1158-1162

Serret A, Borghiani F, Ostrosky C, Moreno D (1994) Relevamiento de poblaciones de huemules en el Parque Nacional Los Glaciares. Fund Vida Silvestre Argentina Bol Técn 24:1-21

Seward NW, VerCauteren KC, Witmer GW, Engeman RM (2004) Feral swine impacts on agriculture and the environment. Sheep Goat Res J 19:34-40

Simberloff D, Relva MA, Nuñez M (2003) Introduced species and management of a Nothofagus/Austrocedrus forest. Environ Manage 31:263-275
Skogland T (1984) Wild reindeer foraging-niche organization. Holarctic Ecol 7:345-379

Smith-Flueck JM (2003) The ecology of huemul (Hippocamelus bisulcus) in Andean Patagonia of Argentina and considerations about its conservation. Dissertation, Universidad Nacional del Comahue, Argentina

Smith-Flueck JM, Flueck WT (2001) Natural mortality patterns in a population of southern Argentina huemul (Hippocamelus bisulcus), an endangered Andean cervid. E J Wildl Res 47:178-188

Stockton SA, Allombert S, Gaston AJ, Martin JL (2005) A natural experiment on the effects of high deer densities on the native flora of coastal temperate rain forests. Biol Conserv 126:118-128

Tomialojc L (1991) Characteristics of old growth in the Bialowieza Forest, Poland. Nat Areas J 11:7-18

Vazquez DP (2002) Multiple effect of introduced mammalian herbivores in a temperate forest. Biol Invasions 4:175-191

Veblen TT, Mermoz M, Martin C, Ramilo E (1989) Effects of exotic deer on forest regeneration and composition in northern Patagonia. J Appl Ecol 26:711-724

Veblen TT, Mermoz M, Martin C, Kitzberger T (1992) Ecological impact of introduced animals in Nahuel Huapi National Park, Argentina. Conserv Biol 6:71-83

Vila AR, López R, Pastore H, Faúndez R, Serret A (2006) Current distribution and conservation of the huemul (Hippocamelus bisulcus) in Argentina and Chile. Mastozool Neotrop 13:263-269

Vila AR, Borrelli L, Martinez L (2009) Dietary overlap between huemul and livestock in Los Alerces National Park, Argentina. J Wildl Manage 73:368-373

Webb SD (1992) A cranium of Navahoceros and its phylogenetic place among New World Cervidae. Ann Zool Fenn 28:401-410

Wehausen JD (1996) Effects of mountain lion predation on bighorn sheep in the Sierra Nevada and Granite Mountains of California. Wildl Soc Bull 24:471-479

Wemmer C (1998) Deer-status survey and conservation action plan. IUCN, Gland, Switzerland

West-Eberhard MJ (1989) Phenotypic plasticity and the origins of diversity. Ann Rev Ecol Evol Systematics 20:249-278

White EM, Wilson JC, Clarke AR (2006) Biotic indirect effects: a neglected concept in invasion biology. Diversity Distributions 12:443-455 